\title{
Lameness and claw lesions in sows, cows and small ruminants ${ }^{\text {th }}$
}

Lameness is a painful and stressful condition with a major impact on welfare, health, and also the productivity of farm animals, in particular sows, cows and small ruminants. It occurs frequently and in general, the problem has become more prevalent in our currently highly selected and intensively raised farm animals. Lameness occurs in varying degrees of severity and may be the result of different underlying conditions. Very often, claw lesions or lesions in the surrounding skin are the main causes. Farm animals need to remain in optimal health to achieve the expected production targets and to deliver healthy products for human consumption. Interfering disease such as lameness and claw lesions may easily disturb the fragile health equilibrium of the animals and lead to an immediate drop in performance and quality of animal products.

The present special issue provides an update of current research and knowledge on lameness and claw lesions in sows, cows and small ruminants. Emphasis is placed on the importance of these conditions, the risk factors and the multifactorial nature of the problem, diagnosis, treatment and last-but-not least efficient control measures. The different papers are written by internationally renowned experts with in-depth knowledge and many years of research and clinical experience in these areas. They have tried to include quantitative data as much as possible when scientific evidence was available. We hope that the special issue may contribute to a better understanding of the problem, may improve the welfare, health and productivity of the animals, the profitability of the farms, and ultimately that it may lead to a more sustainable animal production worldwide.

D. Maes*, G. Opsomer Department of Reproduction, Obstetrics and Herd Health, Faculty of Veterinary Medicine, Ghent University Belgium, Belgium. E-mail address: Dominiek.Maes@UGent.be (D. Maes)

\footnotetext{
This paper is part of the special issue entitled: Lameness and claw lesions in sows, cows and small ruminants, Guest Edited by Prof. Dr. D. Maes and Prof. Dr. G. Opsomer.
}

\footnotetext{
* Corresponding author.
} 